\title{
FORMAR O CIDADÃO: UMA PROPOSTA DA ESCOLA CATÓLICA
}

\author{
Julieta Beatriz Ramos Desaulniers*
}

SÍNTESE - As considerações do presente artigo dizem respeito à formação proposta pelas escolas de ofício católicas aos filhos de trabalhadores, que se localizavam em Porto Alegre/RS, a partir dos fins do século passado até 1970 , cujo processo encontra-se inserido num movimento social mais amplo, voltado à produção do habitante da cidade - 0 cidadão.

\begin{abstract}
The considerations of this article refer to the education proposed by the catholic vocational schools to children of workers in Porto Alegre from the end of the last century until 1970. Its process is inserted in a broader social movement, which is directed towards the production of the city inhabitant - the citizen.
\end{abstract}

O referido artigo tem como principal intenção expor elementos que configuram e distinguem a proposta instaurada em escolas católicas, que foram criadas em Porto Alegre para garantir a formação de futuros trabalhadores, desde os fins do século XIX até 1970.

Nesse sentido, fazem-se algumas considerações sobre o desenvolvimento da industrialização e decorrente urbanização registrados no Rio Grande do Sul e, mais especificamente, em Porto Alegre, a partir do final do século XIX, com o intuito de realçar o processo de produção do cidadão, o individuo que habita a cidade - um mundo que supõe a produção do seu habitante em moldes bem distintos do que 0 meio rural. Nesse tipo de empreendimento, aliás, a Igreja católica e seus representantes têm investido desde que se instalaram no Estado, através de inúmeras ações e estratégias e, assim, imprimiram a sua marca, ao mesmo tempo em que asseguraram e expandiram o seu capital - o capital religioso.'

Professora junto ao Instituto de Filosofia e Ciências Humanas e Mestrado em Serviço Social da PUCRS. E-mail: julietard@music.pucrs.br

1 Os conteúdos apresentados neste texto foram extraídos de DESAULNIERS, Julieta Beatriz Ramos, Trabalho: a escola do trabalhador? - Tese de doutorado, defendida junto ao PPGEd/UFRGS, maio/1993; - resultados de subprojetos em andamento sobre Formação em escolas católicas $P A / R S$, séc. $X I X$ e $X X$, que constam em relatórios parciais e finais enviados aos órgãos financiadores (CNPq, FAPERGS e Pró-Reitoria de Pesquisa e Pós-Graduação/PUCRS). Estas pesquisas articulam-se à linha de pesquisa Formação, Trabalho, Instituição (IFCH/Mestr. Social) e ao Projeto Integrado "Urbanidade e Cidadania: processos de formação e instauração de saberes" (CNPq/FAPERGS).

\begin{tabular}{|l|l|l|l|l|l|}
\hline VERITAS & Porto Alegre & v. 42 & $\mathrm{n}^{\circ} 2$ & Junho 1997 & p. 317-331 \\
\hline
\end{tabular}




\section{1 - Cidade e seu habitante: 0 cidadão}

No Rio Grande do Sul, em decorrência do processo de industrialização, começa a se intensificar o crescimento das cidades em fins do séc. XIX, trazendo consigo novas exigências e necessidades. Outras formas de construção social faziamse necessárias ao contexto que se estava estruturando, desde a implantação de bens e equipamentos que oferecessem as condições básicas de sobrevivência à população emergente, até à instauração de suportes dirigidos mais formalmente à transmissão de saberes que se faziam indispensáveis ao desenvolvimento de tal realidade. Ainda mais que era a cidade que passava a deter o estilo de vida que representaria a configuração social dominante dos próximos tempos.

Essa ruptura, que se estendia para todos os âmbitos da vida em cidade, tinha na industrialização um dos seus principais motores. Tal processo, no Rio Grande do Sul, esteve estreitamente associado ao movimento do capital comercial, que no século passado, para diversificar-se e expandir-se, passou a investir na indústria. A fundação da fábrica Rheingantz registra o início da indústria rio-grandense e, em 1874, já havia em todo o Estado um total de 34 empresas, chamadas "indústrias". Nessa época, foram fundadas, em Porto Alegre, fábricas de navios, serralheria, fábrica de vinagre e cervejaria, que cresciam ao mesmo tempo em que aumentava a população da cidade. Durante o seu primeiro século e meio de existência - 1752/1900 - Porto Alegre foi o núcleo do desenvolvimento agrícola e comercial do centro e do norte do Estado.

É a partir de 1890 que essa cidade entra em franca fase de industrialização. Surgem várias indústrias: Metalúrgica Berta (1891); Cia. de Fiação e Tecidos de Porto Alegre (1891); Cia. Progresso Industrial - Calçados (1892); Fábrica de Móveis (1892); Cia. Fabril Porto-Alegrense (1893); Cia. Fábrica de Vidros Sul-Brasileira (1894); Fábrica de Roupas Brancas e Gravatas (1895); Companhia Manufatora (sem data de fundação).

Porto Alegre, um dos principais pólos de desenvolvimento industrial do Estado desde a sua criação, em 1895, registrava um crescimento equivalente ao do Rio Grande do Sul como um todo e contava na época com trinta sociedades anônimas. Em 1908, havia 314 estabelecimentos industriais na capital, com 15.426 operários; e, em 1916, o número de fábricas era de 9.477 , com um total de 38.488 operários. ${ }^{2}$

Com uma estrutura industrial bastante diversificada, com penetração no mercado da zona colonial onde tinha uma posição privilegiada, e com base regional sólida, após esgotar as possibilidades de expansão junto a esse mercado, Porto Alegre lançou-se no mercado nacional. ${ }^{3}$

Um outro fator decisivo para o crescimento de Porto Alegre, juntamente com seu desenvolvimento industrial, foi 0 da imigração, iniciada nos últimos anos do século XIX e intensificada no decorrer deste. O espaço urbano, mais diferenciado e complexo devido ao aumento populacional - 73.674 habitantes no início desse

2 Relatório da Secretaria da Fazenda do Estado do Rio Grande do Sul. Porto Alegre, 1919, p. 17.

3 SINGER, Paul. Desenvolvimento económico e evolução urbana. SP: Editora Nacional, 1977, p. 173. 
século - precisou de um trabalho de higienização nessa época, para dar fim aos seus "becos" e regiões abandonadas e insalubres.

Vários aspectos do sítio urbano, historicamente problemáticos, especialmente quanto à localização, provocaram a inorganicidade dos espaços, dificultando a circulação e produzindo estrangulamentos e limitações ao crescimento da cidade. Além disso, o processo de urbanização ocorreu de forma bastante desordenada, até aos meados desse século, gerando precariedades e carências na constituição do espaço urbano e na produção de bens de consumo coletivo. ${ }^{5}$

É possivel perceber que o aumento da população carente já se constituía em um verdadeiro problema social, chamando a atenção das autoridades locais, que elaboraram propostas no sentido de buscar soluções para tais questões. Conforme relatório enviado ao Conselho Municipal de Porto Alegre, o intendente José Montaury assinala que "a falta de condições de higiene, de conforto e o elevado aluguel da maior parte das pequenas habitações ocupadas pelos proletários fez com que chamasse vossa atenção para esse fato, sobre o qual convinha à municipalidade alguma providência tendente a minorar essa lamentável situação". ${ }^{.}$Frisa ainda que "as dificuldades de vida, constituindo uma conseqüência fatal do progresso, aqui, como soe acontecer nas grandes cidades, se farão sentir e a resolução dos problemas sociais que se prendem ao bem estar da coletividade devem merecer da administração pública o máximo cuidado, para que não se tornem elas insuportáveis".'

Em termos políticos, o positivismo foi a matriz inspiradora do Partido Republicano Riograndense (PRR), durante sua atuação político-administrativa, que se estendeu ao longo dos quarenta anos da República Velha. Mesmo que a Constituição de 1891 tenha institucionalizado o Positivismo de Augusto Comte, no Rio Grande do Sul verifica-se uma substituição definitiva dessa filosofia por uma versão castilhista. ${ }^{\circ}$ Um dos postulados comtianos que resistiu e até mesmo cresceu em importância foi o da incorporação do proletariado à sociedade moderna. ${ }^{9}$

Por isso, a prioridade dos governos de Júlio de Castilhos e de Borges de Medeiros foi o ensino primário nas escolas públicas, onde se iniciavam a propagação da doutrina positiva e 0 aprendizado de uma profissão. Com a separação entre 0 Estado e a Igreja, porém, os demais setores sociais dedicados ao ensino tinham toda liberdade de traçar os seus rumos no campo educacional. ${ }^{10}$

4 Boletim da Diretoria de Estatística (Secção Demográphica) Ano II - 1909. Porto Alegre: Editora Globo, 191, p. 29 e 35.

- É importante assinalar que, nessa época (1906-1908), ocorreu a instalação dos serviços de tração elétrica nos bondes; o sistema de esgotos foi iniciado em 1908 e inaugurado em 1913. A iluminação elétrica foi instalada em 1907, em substituição à iluminação a gás.

- Relatório e projeto de orçamento apresentados ao Conselho Municipal de Porto Alegre, pelo Intendente Engenheiro José Montaury de Aguiar Leitão, no ano de 1912, p. 18-21.

7 Idem, p. 18-21.

B BOEIRA, Nelson. "O Rio Grande de Augusto Comte". In: DACANAL, J. H. \& GONZAGA, Sergius. RS: Ideologia \& Cultura. Porto Alegre: Mercado Aberto, 1980.

Idem, p. 44.

10 DIL, Aidé Campello. Diretrizes educacionais do governo Antônio Borges de Medeiros (1898-1928). Dissertação de Mestrado. PUCRS/1984. 
Nesse sentido, já em 1891, um político manifestou-se através da imprensa sobre os problemas da crise social e da neutralidade do Estado, destacando que era sua função "manter a ordem material e punir as suas infrações". Na mesma matéria destaca: "Nós que assistimos com a máxima simpatia aos esforços louváveis que são feitos em prol do melhoramento da vida dos proletários, estamos longe de querer que o poder público intervenha na contenda"."

A partir desse tipo de manifestação, fica ainda mais claro que as condições para a instauração de iniciativas voltadas à formação do habitante da cidade estavam dadas pelas características do contexto de Porto Alegre: desde as condições econômicas até a realidade política e social como um todo.

\section{2 - Iniciativas de formação do cidadão e o campo religioso}

Em meados do século passado, mesmo com um processo de industrialização pouco intenso e, portanto, sem o acirramento dos problemas sociais daí decorrentes, algumas iniciativas ligadas à Igreja já se materializavam, constituindo-se, possivelmente, na gênese de um movimento que se intensifica a partir do final desse século. Verifica-se, assim, que a Igreja passou a interferir nas questões sociais ligadas com a produção do cidadão, baseando-se cada vez mais em ações concretas que assegurassem maior consistência ao seu discurso.

A seguir, apresentam-se algumas referências de cunho bem genérico sobre as principais iniciativas que estão sendo pesquisadas no âmbito da linha de pesquisa Formação, Trabalho, Instituição, instauradas a partir de 1860 por representantes do campo religioso, com o intuito de garantirem a formação do habitante da cidade de Porto Alegre que compunha os segmentos populares. ${ }^{12}$

\section{1 - Obras do Pe. Cacique}

Em 1864, o Pe. Cacique - ligado à Diocese de Porto Alegre - funda o Asilo Santa Tereza para meninas órfãs; em 1871, com a fundação da Escola Normal por iniciativa do Estado, passa a colaborar ativamente em sua organização e funcionamento; em 1881, funda o Asilo da Mendicidade para mendigos e decrépitos; em 1892, criou a Sociedade Humanitária Pe. Cacique que congregava as obras por ele já fundadas ou que fossem instituídas a partir dessa data, como foi o caso do Asilo da Mendicidade, que ele inaugurou somente em 1898, assim como o Asilo São

"A Federação. Porto Alegre, 09/06/1891.

12 Mais detalhes sobre isso, consultar as referências indicadas no rodapé n. 1 deste texto, além de artigos elaborados a partir das pesquisas em andamento:

DESAULNIERS, Julieta B.R. "A formação total: um meio de instaurar a Competência?" In: Revista Educação. Porto Alegre: EDIPUCRS, Ano XVII, no. 26, 1994.

- "Um estudo sobre a formação no Pão dos Pobres". In: Revista Integração. Canoas: Editora La Salle, no. 65, 1994.

- "A instituição: um lugar de produção do social". In: Revista Veritas. Porto Alegre: EDIPUCRS, vol. 40, $\mathrm{n}^{\circ} 158$, junho/1995. Texto apresentado no II Congresso Iberoamericano de História de Educação Latinoamericana, Campinas/SP, set./1994.

- . "Instituição escolar e formação" (a ser publicado em inicios de 1997, pela Revista Educação \& Realidade. Porto Alegre: EDUFRGS). 
Joaquim, que teve a sua construção iniciada na virada do século, mas foi concluído em 1932.

Nos estatutos da Sociedade constava que "todos os beneficiários dessa sociedade eram dirigidos segundo os princípios da religião católica", mesmo que fosse uma instituição civil, com finalidades sociais, e mantida através de contribuições espontâneas ou solicitadas pelo Conselho Administrativo. ${ }^{13}$

As iniciativas de formação de segmentos populares, em especial as meninas e jovens, que foram desenvolvidas com o empenho do Pe. Cacique constituem, possivelmente, a gênese de uma nova forma de formar o habitante de cidades gaúchas, que passou a ser instaurada pela Igreja e seus representantes a partir dessa época, através de ações de cunho pedagógico que visavam transmitir saberes práticos, além dos valores e normas da religião católica.

É oportuno incluir nesse item outras iniciativas ligadas ao campo religioso que foram desencadeadas até inícios de 1890. Com a Revolução Federalista, vários chefes de familia sucumbiram, fazendo com que a taxa de orfandade em Porto Alegre, como também em outras localidades, fosse caracterizada como um problema social que podia comprometer esses espaços emergentes. O Pe. João Pereira da Silva, também com o intuito de minorar tal situação, assim como o $\mathrm{Pe}$. Cacique, "idealizou uma obra social destinada a recolher e a dar educação e amparo" a esses órfãos. Adquiriu um terreno no morro Teresópolis e lançou os alicerces dessa obra que denominou "Orfanotrófio". No entanto, sua posição política impediu a concretização desse projeto. Era um federalista fervoroso, "ideal que não ocultava" e, por isso, acusado de estar fundando um espaço destinado apenas aos órfãos filhos de federalistas, não teve o apoio necessário dos vários poderes locais, já que foram os republicanos castilhistas os vitoriosos. ${ }^{14}$

Frente a tal impasse, resolveu doar esse patrimônio à Pia Instituição Protetora da Infância desvalida, fundada pelo Dr. Alinto de Oliveira. Em 1917, ela foi extinta, e o seu fundador fez a doação desses bens ao Pão dos Pobres, que estava sob a direção dos irmãos lassalistas, desde 1916. ${ }^{16}$

\section{2 - Pia União do Pão dos Pobres de Santo Antônio}

Em Porto Alegre, a 15 de agosto de 1895, o Cônego Marcelino de Souza Bitencourt iniciou essa obra na Catedral Metropolitana. Tinha por objetivo distribuir o pão bento de Santo Antônio e esmolas para os pobres e também fazer pregações. Logo depois, começaram a ser atendidas famílias de viúvas pobres no denominado Abrigo, que se situava na Cidade Baixa, na rua que atualmente se denomina rua da República.

Em 2 de abril de 1916, foi inaugurado o Orfanotrófio Santo Antônio do Pão dos Pobres, passando a referida obra para a direção dos irmãos lassalistas. Em 1930, as novas instalações estavam concluídas, tendo capacidade para abrigar aproxima-

Estatuto da Sociedade Humanitária Pe. Cacique, 1911.

PARMAGNANI, p. 14 e 15.

Idem, p. 14 e 15. 
damente 300 meninos órfãos e incluiam o Liceu de Artes e Ofício equipado com maquinário moderno.

Essa instituição constitui-se no caso exemplar dentre as escolas de ofício situadas em Porto Alegre e em outras cidades do Estado, devido à complexidade das suas bases materiais e de gestão. Formara mais de dois mil futuros trabalhadores até 1970 - tipógrafos, marceneiros, mecânicos - sendo os seus formandos muito disputados pelo mercado de trabalho durante todo o período, em especial de 1930 a 1970. Após essa data, verifica-se uma ruptura na formação que se vinha desenvolvendo na maioria das escolas de ofício católicas, que provocou também uma crise visível no processo desencadeado no Pão dos Pobres, bem como nas demais obras.

\section{3 - Colégio São José}

A data de sua fundação é um ponto controvertido. Contudo, há mais indícios em torno do ano de 1924, a qual consta no Livro de Atas da Escola São José, escrito e assinado pelo seu fundador, Irmão Aidant, sendo também citada em artigo escrito por um dos seus diretores, o Irmão Artur.

Localizava-se na mesma área do Instituto Champagnat, no bairro Partenon, dedicando-se à formação de meninos humildes que habitavam nessa região, até meados da década de sessenta. Nesse período, o número de matrículas foi aumentando a cada ano, chegando a atingir mais de duzentos alunos inscritos em 1961.

Essa escola foi desativada por volta de 1964-65, quando suas atividades e funções foram transferidas para a Escola Irmão Weibert, Av. Protásio Alves, Porto Alegre.

\section{4 - Casa do Pequeno Operário}

A Casa do Pequeno Jornaleiro - primeira denominação dessa obra - passou a ser administrada pelo Pe. Mássimi, em 1942, com sede provisória nas imediações do centro de Porto Alegre, rua Sarmento Leite, $\mathrm{n}^{\mathrm{9}} 763$. Assim, inicia-se as atividades da congregação salesiana na capital, que já vinha atuando no estado desde 1927.

O fato de o Pe. Mássimi ser italiano, foi-lhe exigido que se afastasse da entidade com a alegação de que o Brasil estava em guerra contra Itália. Apesar disso, logo que a situação política normalizou-se, o padre retoma o propósito de atender as crianças carentes e busca novas alternativas para dar continuidade a tal empreendimento. Em 1952, consegue fundar a Casa do Pequeno Operário, numa região habitada por trabalhadores, que funciona em regime de internato até 1962, com curso primário e alguma iniciação profissional.

Após 1969, encerram-se as atividades com o internato e cria-se o ginásio orientado para o trabalho. A partir dessa época, verifica-se uma ruptura na orientação que deu origem a essa obra, visto que ela passa a reduzir o atendimento aos segmentos populares. Em seguida, 1972, com a nova legislação do ensino em 1972, implanta-se $\circ 1^{2}$ grau e, em 1975, inicia-se na escola $\circ 2^{2}$ grau, com termi- 
nalidade em técnico em contabilidade e secretariado. Nesse mesmo ano, a instituição passou a denominar-se Escola de $1^{9}$ e $2^{\circ}$ graus Dom Bosco, nome do fundador dos salesianos, mas com uma proposta de formação voltada prioritariamente às camadas médias da população de Porto Alegre/RS.

\section{5 - Educandário São Luiz Guanella}

No ano de 1947, após ter iniciado um trabalho em Santa Maria no Rio Grande do Sul, a Congregação do Padres Servos da Caridade instalou-se em Porto Alegre, na vila Ipiranga, assumindo a responsabilidade do Educandário São Luiz, uma obra destinada ao amparo de menores carentes, que tinha sido fundado por Lydia Moschetti. Em 1948, a congregação dos guanellianos constitui uma sociedade, denominada Sociedade Civil Servos da Caridade constituída por padres e irmãos, sendo a mantenedora de todas as entidades difundidas em diversos estados do Brasil, dentre elas a escola gráfica do Educandário, que começou a funcionar em 1951.

Na década de sessenta, devido às solicitações da comunidade, a referida sociedade instalou outra unidade escolar: o Ginásio Ipiranga. Mas, por entenderem que essa iniciativa estava desviando-se da finalidade principal da entidade - abrigar, assistir e instruir menores pobres, órfãos ou moralmente desamparados ou abandonados - em 1976, cessam as atividades dessa escola, provocando várias mudanças na formação proposta até essa época.

\section{6 - Escola São José do Murialdo}

Essa escola que se situa no Bairro São José, em Porto Alegre, foi fundada em 1954 pelos padres josefinos, como uma das iniciativas integradas à paróquia e à obra social de São José, tendo como mantenedora a Associação Protetora da Infância.

A estrutura e organização dessa instituição é bastante peculiar em relação às escolas de ofício católicas mais antigas, já que oferece uma formação de caráter profissionalizante que procura atender a demanda do mercado de trabalho, incluindo em sua programação desde os cursos rápidos até os mais prolongados, que exigem uma dedicação maior e saberes mais aprofundados dos formandos, em especial aquelas modalidades oferecidas em nivel de $2^{\circ}$ grau, que passou a funcionar a partir da década de setenta.

\section{3 - Uma forma de formar o cidadão: a proposta das escolas de ofício católicas}

Por seguirem os principios da religião ${ }^{18}$ católica, tais escolas apresentam um tipo de organização e funcionamento muito particular, se comparadas com outras instituições que atuavam em atividades similares, nesse mesmo período. Isso se deve, especialmente, ao fato de que essas instituições escolares vinculam-se à

18 Aqui entendida na qualidade de sistema simbólico estruturado, que funciona como princípio de estruturação. In: BOURDIEU, P. A economia das trocas simbólicas. SP: Editora Perspectiva, 1987, p. 45. 
lógica de funcionamento de uma esfera social - o campo religioso - relativamente autônoma em relação a outros espaços, que possui suas próprias estruturas impondo a seus ocupantes um determinado tipo de relações, com regras precisas e jogos próprios:" os agentes, aí, sofrem uma ação pedagógica multiforme, destinada à transmissão de saberes indispensáveis a uma inserção correta nas relações sociais, com destaque para a moralização e sistematização das práticas e das representações religiosas. ${ }^{1 \mathrm{~B}}$

Em outras palavras, os trabalhadores - habitantes de Porto Alegre ou de cidades vizinhas - que fizeram sua formação nessas escolas, até 1970, apresentam características muito próprias e, em vários aspectos, bastante diferenciadas, em relação àqueles que freqüentaram ou não uma escola leiga (particular, estadual/municipal ou ligada a organizações dos trabalhadores), funcionando por turno ou em regime de internato.

Além disso, a Igreja católica e seus representantes instauram através desse processo uma forma pedagógica de formar indivíduos cidadãos, que rompe com a tradicional assistência sócio-religiosa que era prestada aos pobres até aquela época - fins do século XIX, início do século XX.

Face a essa realidade, parece muito oportuno verificar como se tem constitúdo a formação realizada em escolas de ofício católicas, a partir dos fins do século $\mathrm{XIX}$. Nessa perspectiva, apresentam-se as principais dimensões que foram privilegiadas no decorrer de tal processo, ${ }^{17}$ tendo como pressuposto que a descontinuidade verificada na gênese e na estruturação dessas escolas de ofício católicas, como também na formação que elas propunham aos filhos de trabalhadores, estava associada à dinâmica estrutural do campo religioso, que mantinha uma articulação, ao mesmo tempo interativa e conflitiva, com a dinâmica estrutural do campo sócio-econômico-político: o campo do poder.

O fundamento que norteou tal ação pedagógica baseava-se nessa articulação, que é central para as pesquisas que vêm sendo desenvolvidas sobre esse período. $\mathrm{O}$ propósito era formar o homem integral enraizado na força divina, constituindose de saberes vinculados à moralidade cristã, através da ocupação constante do tempo com o trabalho. Este era concebido como uma expressão de reverência a Deus e ao próximo, além de ser o caminho para se atingir a perfeição.

Tais elementos sustentavam-se num conjunto de dimensões que expressam os principais mecanismos e estratégias que asseguraram a produção de um tipo de formado, com base em saberes capazes de conferir-lhe um certo grau de competência ${ }^{\infty}$ para viver em cidade e nela atuar enquanto trabalhador. Isso aconteceu

1 O que ocorre, aliás, com toda organização social que dispöe de maior ou menor autonomia nas relações que estabelece com determinado contexto e traduz, de maneira particular e num ritmo próprio, as mudanças sociais que the afetam. In: PALARD, Jacques. Pouvoir religieux et espace social. Paris: Éditions du Cerf, 1985, p. 19 (Trad. da autora).

18 ACCARDO, Alain. Initiation à la Sociologie. Paris: Éditions le Mascaret, 1983, p. 55, 60, 139 (Trad. da autora).

19 Outras informações sobre esse assunto, em especial sobre a problemática construída para essas pesquisas, consultar DESAULNIERS, Julieta B. R. Formação e pesquisa: condições e resultados. In: Revista Veritas, Porto Alegre: EDIPUCRS, vol. 42, n. 2, jun/1997.

» O tipo de formação voltado à construção da competência baseia-se em relações mais democráticas, a qual começa a ser implantada em tais escolas após 1970, constituindo-se objeto de análise 
apesar de a formação instaurada nessas instituições fundamentar-se principalmente num processo totalizante, de cunho bastante autoritánio sendo então reduzida as oportunidades de autoconstrução e a introdução de dimensões técnicas do trabalho.

\section{1 - Dimensões da formação}

A caracterização principal do processo de formação desenvolvido até 1970 junto às escolas de ofício católicas, pode ser sintetizada na idéia de formar o homem integral, privilegiando a moralização e a sistematização de práticas e representações religiosas, através de uma educação intelectual, profissional, física e social.

Conforme o pensamento de Jean-Baptista de La Salle (1651-1719) - fundador da congregação lassalista e seguido em algumas de suas orientações por outras congregações religiosas em estudo - "o alvo da educação foi, em todos os tempos, formar o homem perfeito. Para a educação católica, o fim da educação é formar o homem sobrenatural que pensa, julga e obra constantemente e coerentemente, segundo a sã razão iluminada pela luz sobrenatural dos exemplos e doutrinas de Cristo"."

Por isso, as dimensões da formação que se instaura em instituições ligadas ao campo religioso configuravam uma proposta sui generis, ao ser comparada com outras formas de produzir o habitante da cidade. É esse, aliás, o entendimento dos seus próprios representantes ao afirmarem que "se se tratasse de ensinar às crianças apenas as Ciências Humanas, os Irmãos não seriam necessários, os professores seriam suficientes. Se não pretendêssemos mais do que transmitir instrução religiosa, contentar-nos-íamos em ser simplesmente catequistas. Nossa finalidade .é integral, porque queremos educar, ${ }^{n}$ ou seja: instruir os educandos em seus deveres, ensinar a praticá-los, transmitir-lhes o espírito e os sentimentos do cristianismo, as virtudes do cristão e do bom cidadão".

As estratégias utilizadas para atingir essas metas encontravam-se, em geral, muito bem especificadas num conjunto de procedimentos que detalhavam tanto a atuação do mestre quanto a do aluno, no tocante a todas as atividades realizadas

das pesquisas em andamento. Sugere-se, no entanto, sobre essa concepção de formação consultar:

- DESAULNIERS, Julieta B. R. (org.). Formação, trabalho, competência: questöes atuais. Porto Alegre: EDIPUCRS, 1977.

- - Formação, competência e cidadania (a ser publicado em: Revista Educação \& Sociedade, Campinas: CEDES, 1997).

- SLVA, Inês Amaro da. "Competência e cidadania no mundo do trabalho". In: Revista Veritas, Porto Alegre: EDIPUCRS, vol. 42, n. 2, jun/1997.

21 JUSTO, R. Henrique. La Salle, patrono do Magistério - vida, biografia, pensamento, obra pedagógica. PA: Livraria Santo Antônio, 1961, p. 165.

a A expressão educar nesse contexto, refere-se a um processo que visa atingir uma determinada forma, através de um conjunto de pressupostos que configuram os interesses e necessidades de uma dada realidade social, tal como é entendida no âmbito dessa pesquisa, a categoria de análiseformação.

21 In: Revista Inter-Provincial de Reflexão e Comunicação, s/e, ano 14, n. 53, p. 52. 
no ambiente escolar, que funcionava em regime de internato fechado, envolvendo o aprendizado de um oficio, em especial, tipografia, marcenaria e mecânica.

Uma das referências mais importantes ao processo de formação realizado em escolas de ofício católicas tem sido a obra escrita por Jean-Baptista de La Salle e os primeiros Irmãos, intitulada "Conduite des Écoles Chrétiennes". " Divide-se em três partes. A primeira trata de todos os exercícios a serem praticados na escola, desde a entrada até a saída do aluno; na segunda, são apresentados os meios, necessários e úteis, dos quais os mestres devem se servir para estabelecer e manter a ordem na escola: e, por último, a terceira parte especifica: a) os deveres do diretor da escola; b) as características do orientador de novos professores; c) as qualidades de um professor; d) os deveres do alunos. ${ }^{25}$

Verifica-se, assim, que a formação do cidadão proposta por representantes do campo religioso, além de ser orientada pelos conteúdos da religião católica e da Igreja enquanto instituição milenar - de caráter universal, seguia também um conjunto de pressupostos devidamente sistematizados nas obras dos fundadores das ordens ou congregações religiosas, como a Conduite ${ }^{\star}$ (e outros tratados elaborados por La Salle sobre deveres e regras de obediência e de disciplina).

Para essa forma de formar, o desenvolvimento das aptidões individuais era fundamental: os formandos deveriam ser acompanhados regular e constantemente pelos mestres em tudo, mesmo nas atividades extra-classe. O sistema de vigilância precisava ser rigoroso para que o mestre pudesse, por conhecer minuciosamente o seu aluno, atender às suas reais necessidades, em cada momento.

Segundo Champagnat, "uma das características dos educadores religiosos, especialmente dos maristas, era justamente a presença constante, atenta e amiga do educador junto ao educando" - à qual atribuía a denominação de Pedagogia da Presença. ${ }^{n}$ Assim, garantia-se que o formando ficasse sob os olhares de um superior - diretor, prefeito de disciplina, professor, mestre de oficina ou chefe de equipe, um colega da turma dos maiores - sendo obrigado a comportar-se, durante todo o tempo e em todos os espaços, de acordo com as normas estabelecidas, para atingir a perfeição. ${ }^{\sharp}$

Associado a isso, destacava-se o exemplo dado pelas primeiras figuras que serviam de referência aos internos - Jesus Cristo, os fundadores da congregação e da escola, além do diretor e dos mestres (em geral, padres ou irmãos). Suas vidas eram constantemente lembradas como experiências que continham, mesmo em diferentes graus, os aspectos básicos da virtude, da sabedoria, da disciplina e da santidade. Por isto, todos, indiscriminadamente, precisavam espelhar-se nesses

${ }^{24}$ LA SALLE, J.-B. de. Conduite des écoles chrétiennes (ediçäo organizada por ANSELME, F., com introdução de notas comparativas), Paris, Rue de Sèvres, 1951.

2s Idem, p. 6 (referente à parte manuscrita que foi editada, com tradução da autora).

2 Essa obra, por exemplo, foi apresentada por M. Champagnat, na condição de fundador da Congregação dos Irmãos Maristas, como o Guia Didático a ser seguido pelos seus Irmãos, e que ainda hoje tem a sua utilidade. In: ZIND, Pierri. $O$ bem aventurado Marcelino Champagnat, Editora Centro de Estudos Maristas, s/d, p. 204.

It Idem, p. 113.

r Considerações mais detalhadas sobre isso In: DESAULNIERS, Julieta B. R. "O controle do tempo e do espaço: um meio de formação". Texto apresentado do XVI Congresso Intemacional de Histónia da Educação - ISCHE, Amsterdã/Holanda, agosto/1994. 
exemplos, para consolidar uma formação sadia, plena de caráter. Para tanto, sabiase que era indispensável contar com alunos nas faixas etárias mais propícias à assimilação de novos padrões e valores, que se situavam na infância e primeiros anos da adolescência.

A formação pelo exemplo, nesse contexto, instaurava no formando sentimentos bastante contraditórios, o que garantia uma eficácia maior ainda a tal processo. De um lado, ele se via como o menor, o menos privilegiado, diante do seu modelo; por outro, o aluno concluía que, mesmo assim, era um dos "escolhidos" dessas figuras, o que servia, evidentemente, para reconfortá-lo e fazê-lo sentir-se um privilegiado, apesar da sua condição de órfão e de "desvalido da sorte".

Desse modo, os pressupostos de caráter essencialmente religioso, nos quais os processo de formação dessas escolas de ofício católicas estavam imersas, eram transmitidas aos alunos por meio de uma vivência prática e concreta, que permeava todo o seu cotidiano.

O grande instrumental utilizado para construir esse tipo de formação foi, sem dúvida, o trabalho imposto aos alunos, fosse ele realizado numa situação de ensino-aprendizagem, trabalhando em sala de aula, nas oficinas, no estudo de um instrumento musical, de um esporte ou do catecismo ou em atividades extraclasse (auxiliando nos refeitórios, arrumando os dormitórios e banheiros, varrendo os pátios e outras áreas, fazendo a sua higiene pessoal, vigiando seus colegas). Fora os raros momentos de puro lazer, com horário, local e atitudes bem definidos, os alunos estavam sempre envolvidos no trabalho, com tarefas e responsabilidades a cumprir, num dado tempo e sempre sob determinadas exigências.

Havia um cuidado constante em manter os alunos sempre bem ocupados e sob o controle de um mestre, do prefeito de disciplina ou de um aluno para isso nomeado, conforme já foi mencionado anteriormente. Assim, esperava-se evitar a presença de maus pensamentos e atitudes, que poderiam ameaçar uma formação que se pretendia austera, baseada numa rígida disciplina. Além disso, conforme D. Bosco, a espiritualidade devia estar calcada numa vida repleta de trabalho e não de tempo livre.

Por essas razões, concebia-se o trabalho como um ato de virtude entre $\circ$ homem e a natureza, fonte de desenvolvimento da espiritualidade e de combate à indolência e à ociosidade, a ser realizado com intuito competitivo, baseado na austeridade e na disciplina.

* Isso era constantemente dito ao interno órfão - os candidatos preferencias de tais escolas nesse período - para que ele não se esquecesse de quem era quando chegou no orfanato e quais as possibilidades que passou a usufruir nessa instituição, como um privilegiado, "um dos escolhidos de Deus". Informações colhidas junto aos arquivos das escolas pesquisadas.

3 Tal dimensäo era muito enfatizada no discurso religioso dominante nessas escolas. Dentre as várias evidências, cita-se a seguinte anotação feita pelo provincial dos Irmãos lassalistas, ao visitar a escola Pão dos Pobres: "[...] Ensinai-lhes a santificar o trabalho nas oficinas, a exemplo do Divino Operário. Fazei tudo para conseguir a perseverança deles [...]” In: Livro de Registros, 05/07/1955, fl. 43 .

${ }^{31}$ Fundador da congregação dos padres salesianos, no século XIX, na Itália, que também adotou certas orientaçōes propostas por J.-B. de La Salle. 
Partia-se também do princípio de que todo tipo de trabalho, mesmo aquele voltado mais diretamente para a qualificação profissional do aluno, devia ser aprendido através da prática. Ou seja, aprendia-se a fazer fazendo, desenvolvendo hábitos pessoais de estudo, planificando as ações e dedicando-se ao trabalho, com total repulsa à ociosidade. O tempo dedicado a atividades de cunho teórico era bastante reduzido. As aulas de conhecimentos gerais, por exemplo, eram administradas nos momentos de intervalo do aprendizado do ofício, ou à noite, após a realização das demais tarefas.

Um dos fatores que reforçava a interiorização e individualização dos formandos, além de impor-lhes um ritmo menos dispersivo ao trabalho, era o silêncio, ao qual se atribuía grande importância. Em algumas atividades, inclusive, o silêncio era uma exigência tal que o próprio mestre, para se dirigir aos pupilos, só recorria à palavra como último recurso. Para que essa exigência fosse cumprida de forma mais efetiva, La Salle criou um sistema de sinais que substituiam a palavra, os quais eram expressos por meio de um instrumento de madeira. ${ }^{x}$

Vale observar que esse silêncio supunha a atenção constante, tanto do aluno quanto do mestre. Isso fica bem claro no Guia da Escolas dos Pequenos Imãos de Maria, de 1923, em que "[...] O mestre silencioso é aquele que emprega a palavra com moderação, poupando-a de bom grado quando um gesto ou um sinal for suficiente; que somente se faz ouvir quando os alunos estão atentos [...]".."

Além das normas gerais, dirigidas a todos, havia orientações dadas individualmente, a cada interno, exercendo forte pressão sobre suas atitudes e comportamentos. Assim, o órfão tinha poucas oportunidades de burlar o estabelecido, conformando-se com o que lhe era proposto, sem maiores resistências. Tudo isso, certamente, marcou indelevelmente a vida dos formandos em escolas de ofício católicas.

Havia, contudo, algum incentivo à inventividade; e, mesmo que todo esse processo de formação tivesse como conseqüência uma inserção submissa nas relações de produção, propiciava alguma mobilidade e certa ascensão social. Isso é explicitado no depoimento de um Irmão, ao mencionar os conselhos que dava aos formandos que estiveram sob a sua orientação durante várias décadas: “[...] vocês têm que, no mínimo, chegarem a chefes de setor, senão até donos, de uma gráfica, de uma marcenaria, de ter a sua coisa própria[...]". ."

Assim, o processo de formação das escolas de ofício católicas em estudo consistia no desenvolvimento de todas as capacidades do aluno, que se realiza de um lado, pela inculcação de uma forte concepção ética e moral baseada em princípios religiosos e, de outro, propunha uma iniciação gradual, para que o formando se tornasse capaz de incrementar suas próprias potencialidades técnicas, que passavam a ser exigidas do trabalhador urbano - um dos segmentos sociais mais numerosos que habitava a cidade.

É importante salientar que as bases que asseguraram a implantação desse processo - uma das formas de formar o cidadão - foram produzidas a partir de um

32 JUSTO, op. cit., p. 203.

33 ZIND, op. cit., p. 213.

3 Depoimento colhido em dez/1990, na escola Pão dos Pobres. 
jogo de interesses entre os representantes dos vários setores sociais. A concretização desses interesses, igualmente, deu-se nesse mesmo jogo de relações e, assim, foram sendo construídas as novas estruturas que se inscreviam, a cada momento, na dinâmica de tais escolas. ${ }^{*}$

Em outros termos, o referido processo dispunha, a partir desses elementos, das possibilidades necessárias para implantar um "sistema de disposições duráveis e transponiveis, estruturas estruturadas, predispostas a funcionar como estruturas estruturantes". Desse modo, consegue neutralizar o mais possivel as experiências passadas dos internos, mesmo se estas sempre tenham exercido o papel de filtro em relação às novas práticas que foram assimiladas ${ }^{n}$ e transmitidas aos futuros trabalhadores cidadãos, que foram produzidos nessas instituições de formação. $\mathrm{E}$, assim, os saberes aí instaurados auxiliaram a "constituir o campo religioso como mundo significante, dotado de senso e de valor, no qual faz sentido investir energia", o que resultou "numa verdadeira cumplicidade ontológica", que uniu o formado ao mundo social, cada vez mais exigente de uma postura sustentada na urbanidade.

Vários fatores, oriundos tanto da dinâmica estrutural do próprio campo religioso, como das repercussões advindas da sua articulação com a dinâmica estrutural dos campos social, econômico e político, alteraram no decorrer do tempo, de maneira bastante acentuada, a forma de formar o cidadão proposta pelas escolas de ofício católicas pesquisadas. ${ }^{\text {n }}$

Pouco a pouco, o caráter religioso e transcendental, fortemente associado ao domínio do ofício, passa a ser relativizado. Do mesmo modo, é subestimada a noção de que todo tempo livre devia ser transformado em tempo de trabalho, bem como a idéia de que, para isso, era fundamental a manutenção dos alunos em regime de internato fechado. Assim as exigências quanto a uma disciplina rígida $e$ ostensiva já não tinham fundamento prático.

Enfim, é provável que todas as gerações de estudantes, formadas por essas escolas após 1970, deixem de ser constituidas conforme os padrões iniciais, por inexistirem estruturas capazes de sustentar a produção do processo nesses moldes. ${ }^{n}$

3o Nesse sentido, consultar DESAULNIERS, Julieta B. R. A Instituição: um lugar de produção do social. In: Revista Veritas. Porto Alegre: EDIPUCRS, vol. 40, $\mathrm{n}^{2} 158$, junho/1995. Texto apresentado no II Congresso Iberoamericano de História de Educação Latinoamericana, Campinas/SP, set/1994.

3 BOURDIEU, P. Le sens pratique. Paris: Éditions de Minuit, 1980, p. 88 (Trad. da autora).

Idem, p. 89.

BOURDIEU, P. Réponses - pour une anthropologie réfléxive. Paris: Seuil, 1992, p. 103 (trad. da autora).

39 Isso está bem demonstrado em alguns textos traduzidos que estão publicados neste número da revista Veritas, especialmente os textos de FAGUER \& BALAZS e Lucie TANGUY.

40 As pesquisas em andamento, que se vinculam à linha de pesquisa Formação, Trabalho, Instituição, estão centradas nessas questões que passam a constituir a realidade das escolas católicas voltadas aos segmentos populares, em especial, a partir da década de setenta. 


\section{4 - Considerações finais}

É indiscutível que a força e a influência dessa forma de formar permanece por muito tempo na vida dos seus formados, como eles mesmos confirmam. As revelações de um formado numa das escolas de oficio católicas investigadas são exemplares nesse sentido, quando ele diz: "[...] A ligação com os Irmãos lassalistas foi muito forte e se estende até hoje; digo que meu segundo lar são os lassalistas. Hoje dou assistência para os Irmãos na construção de prédios, nas reformas. A afeição, o dever de gratidão para com eles é algo muito forte".

$\mathrm{Na}$ medida em que a formação era totalizante, baseando-se num conjunto de pressupostos que visava à homogeneização das atitudes e comportamentos dos internos, as oportunidades de diversificação das experiências no ambiente de tais escolas eram reduzidas, fazendo com que todos, independente da época em que lá estiveram, fossem obrigados a vivenciar praticamente as mesmas situações. Sendo assim, o que vale destacar, é a forma como esse processo inscreveu-se nas memórias, nos corpos, impregnando a vida inteira dos seus formados.

Esse é um dos aspectos mais relevantes de tal análise ao contexto atual, especialmente aos segmentos populares da nossa sociedade. Verifica-se que o sucesso dessas instituições estava diretamente associado à estrutura dos tempos e espaços, materializados em práticas e saberes ai construídos, que possibilitaram as rupturas que eram capazes de instaurar as disposições exigidas para uma inserção social adequada desses indivíduos enquanto cidadãos. Ou seja, o processo de incorporação do habitus que caracterizava e distinguia o habitante de cidades até 1970, estava sendo instaurado em escolas de ofício católicas - uma forma de formar o cidadão - através de experiências concretas que, ao serem repetidas, acumulavam-se, sobrepunham-se e se acumulavam, interionizando-se sempre mais profundamente, até se transformarem em disposições gerais.

Ainda, através das pesquisas foram reelaborados elementos relativos à constituição de futuros trabalhadores cidadãos que realizaram a sua formação em instituições escolares ligadas ao campo religioso. Assim, ao recuperar a memória e a identidade desses agentes sociais, novos subsídios estão sendo colocados à disposição e podem revitalizar esse processo de produção do cidadão.

Em outros termos, são resgatados aspectos da História da Educação do Rio Grande do Sul, com a sistematização de dados e referências de uma época, que com o tempo ficariam perdidos, pois estavam dispersos e sem qualquer tipo de sistematização. Uma parte dessas informações continuam sendo "bens" que estão com as pessoas - em suas memónias e lembranças - muitas das quais já morreram ou estão bastante idosas. Se essas histórias não forem registradas com urgência escritas, catalogadas, analisadas - a socialização desses conhecimentos ficará comprometida, restando somente uma histónia de lacunas perenes. E, então, por não se possuir uma visão nova do passado fica dificultada a aquisição de uma visão nova do futuro."

4T ZELDIN, Theodore. Uma história intima da humanidade. RJ-SP: Record, 1996, p. 7. 
Finalmente, destaca-se que a abordagem utilizada nessa pesquisa instaura uma ruptura com o objeto pré-construído - que está envolvido de significações de nível inferior, ligadas à experiência mais ingênua e aparente ${ }^{2}$ - e propõe um referencial de análise para considerar o objeto que está sendo investigado. Nessa perspectiva, entende-se que o modelo explicativo construído para capturar a formação produzida em escolas de ofício católicas, por estabelecer uma articulação desse processo à dinâmica mais geral da sociedade, pode ser utilizado para analisar outras realidades semelhantes. Assim, procura-se contribuir, em alguma medida, para uma maior compreensão de tal fenômeno, com a possibilidade de se atingirem algumas generalizações quanto ao papel e as ações do campo religioso que, através de suas práticas pedagógicas ligadas às representações associadas às normas e valores do catolicismo, dedicou-se a um empreendimento que tem sido do interesse de vários outros segmentos sociais: 0 de formar o futuro trabalhador que habita a cidade.

12 Conforme concepção de PANOFSKY. In: BOURDIEU, P. A economia das trocas simbólicas. SP: Perspectiva, 1987, p. 338 e 339. 